\title{
Análise das narrativas de uma preceptora alemã sobre a educação brasileira
}

\author{
Analysis of the narratives of a german preceptor on brazilian education
}

\author{
Ana Maria Antunes de Campos \\ Doutoranda em Educação Matemática da PUC-SP \\ camp.ana@hotmail.com
}

\begin{abstract}
Resumo: Este artigo tem como objetivo refletir sobre a importância dos textos literários para análise da História da Educação. Para isto, foi analisado o livro "Os meus romanos" da autora Ina Von Binzer, com vistas a compreender a educação no período de 1881 a 1884 , momento em que a autora atua como preceptora em casas de famílias brasileiras. Binzer escreve diversas cartas e as envia à Grete, revelando os diferentes pontos de vistas de uma imigrante recém-chegada ao Brasil, o que permite ao leitor uma reflexão sobre escravidão, política, economia, cultura e educação em uma época de grandes mudanças no país. Isto posto, por meio deste texto busca-se compreender como as fontes literárias se tornam objeto de investigação para a organização e constituição da história.
\end{abstract}

Palavras Chaves: História da Educação, Ina Von Binzer, Literatura.

\begin{abstract}
This article aims to reflect on the importance of literary texts for the analysis of the history of education. For this, the book "My Romans" by the author Ina Von Binzer was analyzed, with a view to understanding education from 1881 to 1884 , at which time the author acts as tutor in Brazilian families' homes. Binzer writes several letters and sends them to Grete, revealing the different points of view of a newly arrived immigrant to Brazil, which allows the reader a reflection on slavery, politics, economy, culture and education in a time of great changes in the country. This fact, through this text seeks to understand how the literary sources become object of investigation for the organization and constitution of history.
\end{abstract}

Keywords: History of Education, Ina Von Binzer, Literature. 


\section{Investigando a obra literária}

O livro Os meus romanos foi escrito pela autora Ina Von Binzer que esteve no Brasil entre os anos de 1881 a 1884 no qual atuou como preceptora no período que antecede a Abolição da Escravatura. Segundo o prefaciador Paulo Duarte, este livro foi publicado em português pela Editora Anhembi em 1956. O livro é fundamentado nas cartas que a autora escreve para sua estimada Grete, descrevendo sobre o tempo que permaneceu no Brasil. Binzer durante o texto utiliza o pseudônimo de Ulla Von Eck.

Ao ler os prefácios da primeira e segunda edição do livro, percebesse que existem diversos questionamentos com relação à obra e a autora. Antônio Callado (1991) que faz o prefácio da segunda edição esteve em Berlim pouco depois de ler a obra e buscou informações sobre Ina Von Binzer onde encontrou um verbete que apresenta informações sobre quando a autora nasceu (03 de dezembro e 1856), onde estudou e como foi o eu retorno para Berlim após essa temporada no Brasil.

Paulo Duarte (1991) que redigiu o prefácio da primeira edição também possuía alguns questionamentos sobre a obra e autora. Em suas investigações ele descobre que o primeiro ano de publicação do livro Os meus romanos foi em 1887, essas informações segundo Duarte (1991) estão registradas nos Anais da Biblioteca Nacional de Belo Horizonte, no entanto, para ele esses dados divergem das informações que possuía, pois no exemplar original a data citada é de 1856, Duarte (1991) acredita que esta seja a data do nascimento de Ina Von Binzer.

Outra discussão que surge ao ler a obra é o gênero literário. Seria um texto auto referencial? Uma autobiografia ou um romance epistolar? Segundo Vinão (2004) as cartas ou correspondência se estabelecem como um tipo de documento auto referencial, entretanto a autora utiliza técnicas literárias desenvolvendo a história por meio de cartas, o que pode constituir o texto em um romance epistolar. Por outro lado, a obra ainda apresenta uma relação entre autor, narrador e personagem e segundo Alberti (1991) essas relações implicam na autobiografia, ou seja, "significa dizer que os três elementos podem não constar em todas as páginas de uma autobiografia, sendo apenas predominantes, mas que a identidade entre autor, narrador e personagem é condição sine qua non de uma autobiografia”. (ALBERTI, 1991: 10).

Compreende-se que não é simples definir que tipo de obra foi escrita por Binzer, contudo essa não é uma particularidade apenas dessa autora, uma vez que segundo 
Hobsbawm (1990: 21), "todos os tipos de história enfrentam problemas técnicos, próprios, mas a maioria supõe que há um conjunto de material informativo pronto e à disposição e cuja interpretação é que os cria".

A análise dos textos históricos e literários permitem uma maior compreensão das questões políticas, sociais e econômicas de um determinado período. Para Pesavento (2003: 32):

As questões que articulam o debate, que aproximam e entrecruzam as narrativas histórica e literária, entendendo-as como discursos que respondem às indagações dos homens sobre o mundo, em todas as épocas. Narrativas que respondem às perguntas, expectativas, desejos e temores sobre a realidade, a História e a Literatura oferecem o mundo como texto.

Independente do gênero literário, das divergências de dados e da falta de informação sobre a autora, o livro traz informações significativas sobre o Brasil em um período de grandes mudanças políticas e econômicas que antecederam a Abolição da Escravatura e a Proclamação da República e proporciona uma reflexão para os leitores acerca da educação brasileira, da cultura e política.

Ina Von Binzer analisa criticamente o Brasil e descreve essas observações em suas cartas repletas de sentimentalismo, saudosismo e criticidade. O livro expressa o olhar do imigrante diante do Brasil levando o leitor a refletir sobre escravidão, política, economia, cultura e educação em uma época de efervescentes mudanças no país.

No período que Ina Von Binzer esteve em solo brasileiro a econômica e política sofriam mudanças significativas e em vista disto a área educacional estava em busca de transformações, segundo Mortatti (1999) o intuito era se desvincular do atraso do império, ou seja, a substituição do antigo pelo novo, que regia a evolução social rumo ao progresso, neste momento a educação era vista como um dos instrumentos de desenvolvimento. “[...] preocupações com o ensino da língua materna são também as de uma época que, aspirando por reverter o "atraso horroroso" e o "sofisma do império" e baseando-se em um projeto de fundação de uma civilização nos trópicos, enfatiza a importância da aprendizagem da leitura, mediante a disseminação da instrução pública" (MORTATTI, 1999: 44). 
Imbuídos dessas preocupações é possível se conjecturar que as famílias abastadas mesmo sem instruções educacionais, visavam adquirir os saberes científicos e os "ensinamentos modernos da educação" para seus filhos. Dessa forma a preceptoria era a forma mais individualizada de instrução, portanto muitas crianças e jovens eram instruídos em seus lares e para tal eram necessárias as mentoras.

Neste período as mulheres eram criadas para exercer a função de mãe e esposa. Quando não se casavam na idade prevista, tornavam-se enfado às famílias, pois não estavam desempenhando o papel para o qual foram designadas. Isto posto, um caminho possível para essas mulheres desprovidas de dinheiro e sem sorte de casamentos, era a busca por uma colocação na sociedade por meio de trabalhos como preceptoras e governantas.

Segundo Ritzkat (2000: 275), no período em que Binzer atuou no Brasil, existia outras preceptoras alemãs que trabalhavam em São Paulo, dentre elas: "Fräulein Harras e Fräulein Meyer; Ida Bausch (1856-1915), Anna Valerie Von Bethge (1858-1914) e Hildegard Maria Schröder (falecida em 1936)".

As famílias abastadas publicavam anúncios nos jornais locais solicitando os serviços de preceptoria. As preceptoras tinham como incumbência a educação escolar, moral, ética e para as meninas a educação comportamental para que pudessem participar da sociedade enquanto damas. Segundo Moraes: “era também costume dessas famílias abastadas, em geral enriquecidas pela cultura da cana-de-açúcar e, depois, do café, contratar professores particulares para a educação de seus filhos, principalmente no caso das mulheres." (2006: 47).

Desse modo, podemos compreender que a família da fazenda São Francisco, que contratou inicialmente Ina Von Binzer tinham posses e em uma de suas primeiras cartas a autora revela que ao que parecia "todo brasileiro bem colocado na vida tinha o direito ao título de doutor" (18).

Ina Von Binzer em sua carta inicial relata que todos os brasileiros pareciam falar francês, conjectura-se que no final do século XIX chegavam ao Brasil, imigrantes de muitos países cada um com um interesse e motivo, alguns visando o comercial, outros pelas expedições científicas e alguns pelas novas colocações profissionais nas estradas de ferros, fazendas e olarias, deste modo era necessário aprender alguns idiomas para poder comunicar-se com esses imigrantes que buscavam novas oportunidades no Brasil. 
O alto poder de acumulação, característico dos últimos anos da década de 1870 e dos primeiros da década seguinte, sugere a alguns estudiosos a impossibilidade - vista por muitos fazendeiros da época - da permanência do escravismo no café, dados o término do tráfico e os impedimentos à criação de escravos no país para ampliar a força de trabalho. A restrição da oferta de escravos, com significativa elevação dos preços, teria levado esses fazendeiros a optar pelo trabalho livre. (MORAES, 2006: 82).

Segundo Sevcenko (2003), a literatura é uma fonte e cabe ao historiador a interpretação da história, dos elementos que descrevem alguma coisa sobre o autor, sobre o ponto de vista referente à vida e o período retratado na obra. O livro de Ina Von Binzer deixa transcrito suas fortes críticas ao Brasil, durante todo o volume são escritas quarenta cartas a Grete, em cada epistola Ina Von Binzer relata suas observações sobre o Brasil que transpassa por ritos, rituais, comida, leis, negros, faunas, flora, doenças, escravatura, cultura e acima de tudo as práticas educacionais.

Infelizmente não existe nenhum documento que possa comprovar a veracidade dos fatos vividos por Binzer, contudo os erros da autora são "menos graves em suas consequências que as omissões da história oficial". (BOSI, 1994: 1). O interesse em analisar o texto da autora está relacionado com a investigação da história da educação no contexto social apresentado por Binzer que, permitem situar suas lembranças acerca do Brasil em um período de efervescência política, cultural e social.

Ina Von Binzer iniciou seus trabalhos no Brasil lecionando para sete dos doze filhos do contratante, durante sua estadia nessa fazenda ela reclama do trabalho excessivo, da postura das crianças que eram más educadas, com atitude de superioridade devido à escravidão existente, da distância entre os vizinhos que chegavam a uma extensão de cinco milhas uns dos outros, relata que os alunos queriam “engolir cultura ás colheradas", pois nunca tinham tempo livre e ainda assim considerava o ensino brasileiro como superficial. "Não consigo habituar-me a esse ensino superficial; mas, quando começo a me aprofundar ainda é pior: fico completamente desanimada" (87).

Ina Von Binzer estranha a forma como o negro é tratado, considerado como mercadoria e posse de outra pessoa, em suas cartas ela revela a resignação dos escravos mediante aos seus senhores. 
O Dr. Rameiro, em pessoa, veio buscar-me à estação e calcule, minha querida, numa comodíssima carruagem europeia! Nunca um semitorre me desapontou tanto quanto este. Se ao menos pelo caminho se tivesse partido uma das rodas ou se o cocheiro preto (este sim, um autêntico escravo) tentasse jogar-nos num despenhadeiro para vingar-se de algum castigo recebido. Mas, devo confessar humildemente que ele nos observava com bondade, olhando-nos de cima do seu narigão chato, sem pensar em nenhum precipício (BINZER, 1994: 17).

A autora critica ainda a falta de atividade dos brancos que nada faziam, ou seja, toda riqueza era adquirida por mãos de negros e só esses trabalhavam. Também faz uma crítica sobre a lei que foi promulgada em 28 de setembro de 1871 da qual os negros que a partir daquele momento nascessem, seriam libertos.

Mas não é assim. Foi determinado que do dia de sua promulgação em diante, 28 de setembro de 1871, ninguém mais nasceria escravo no Brasil. Quem já vivia como cativo nessa época assim permanecerá até a morte, até o resgate ou até a libertação. Os pretinhos nascidos agora não têm nenhum valor para os seus donos, senão de comilões inúteis. Por isso não se faz nada por eles, nem lhes ensinam como antigamente qualquer habilidade manual, porque, mais tarde, nada renderão. Como são livres, porém, os brasileiros tratam-nos com mais estima e maior consideração do que os escravos natos (BINZER, 1994: 40-41).

No entanto, para Binzer esses escravos passavam a não ter valor para os seus donos afinal eram livre e se constituíam um estorvo, porquanto nada rendiam e como livres nada se fazia por eles. Para a autora os negros libertos não sabiam o significado de liberdade, pois "não se pode exigir dessa raça que se acha escravizada há tantas gerações, concepções pessoais altamente civilizadas, nem pretender que adotem nossos conceitos sobre a liberdade, em relação ao homem, e de honra em relação à mulher, o que seria uma vã aspiração poética.” (BINZER, 1994: 41).

Ina Von Binzer em uma de suas últimas cartas, revela suas observações com relação ao quanto o brasileiro sofrerá com a abolição, porque não se decidiram pela emigração europeia, pela extinção da força trabalhadora e por que apresentarão muitos elementos inúteis nas ruas, livres e sem produtividades. 
Autora retrata diversas vezes sobre as desigualdades sociais, crítica nossa cultura e diversas vezes nosso desperdício e mau aproveitamento do solo.

Do ponto de vista dos nossos países o que se faz aqui em São Sebastião com as madeiras é um verdadeiro esbanjamento; assim, minha cômoda tosca e mal-acabada é toda de cedro, com os móveis rústicos da sala de aula, que também são fabricados com material precioso. Mais um exemplo de muitos desequilíbrios que existem neste país: esbanjamento de um lado, penúria do outro... (BINZER, 1994: 135).

Ina Von Binzer não fica apenas na fazenda que a contrata inicialmente, a autora adoece e necessitando de cuidados médicos parte para o Rio de Janeiro com vistas a consultar um médico. A autora só retorna à fazenda São Francisco para despedir-se e comunicar sua partida definitiva, pois decide permanecer no Rio de Janeiro.

\section{0 trabalho retratado por meio das epístolas}

No Rio de Janeiro a autora inicia um novo trabalho como professora do Liceu de moças, com pensionato, onde tem que lecionar para quatro classes de inglês e alemão, além das aulas de piano. No entanto sua estadia nesta instituição é curta, pois não se acostuma com o pensionato, nem com os alunos, sua metodologia fracassa e sua frustração aumenta por não conseguir colocar em prática seus métodos de ensinos.

Nas últimas décadas do século XIX a mulher passa a ser vista como uma pessoa com muitos atributos e virtudes para o cuidado e a guarda natural da criança e, por questões morais a sociedade passa a investir na formação de moças criando liceus e escolas preparatórias para o trabalho feminino no campo da educação.

A mão de obra feminina na educação principiou a revelar-se necessária, principalmente tendo em vistas os impedimentos morais de professores de educar as meninas e a recusa da sociedade a coeducação dos sexos, considerada perigosa do ponto de vista moral[...] Essa ideologia teve o poder de reforçar os estereótipos e a segregação sexual, pois se entendia que cuidar 
de crianças e educar era missão feminina, por isso o magistério se revela como seu lugar por excelência. (VALDEMARIN, 2006: 136).

No Liceu de moças, Ina Von Binzer relata um dos episódios sobre a indisciplina escolar e deixa clara a divergência de métodos educacionais empregados, porquanto para os alemães um dos castigos mais vergonhosos para os alunos é levantar e sentar cinco vezes seguidas, ao tentar aplicar essa punição nas crianças brasileiras, autora expõe que as crianças compreenderam o corretivo como uma brincadeira. Ina Von Binzer vem para o Brasil com um ideal de práticas educativas, como se fossem civilizar os alunos ao aplicar seus métodos, no entanto descobre que é imprescindível um método de ensino que satisfaça a necessidade dos alunos brasileiros e não um ensino no modelo europeu. "Reconheço ser indispensável adotar-se uma pedagogia aqui, mas ela deve ser brasileira e não alemã, calcada nos moldes brasileiros e adaptada ao caráter do povo e às condições de sua vida doméstica". (BINZER, 1994: 87).

Após o episódio no liceu Ina Von Binzer procura o cônsul alemão no Rio de Janeiro, com o intuito de orienta-la ele indica que ela coloque um anúncio no Jornal do Comercio sobre os préstimos de seus serviços, buscando uma colocação na província São Paulo. Os periódicos nesse momento se revelavam enquanto vozes, ou seja, um meio de comunicação da sociedade, para conhecimento dos acontecimentos vigentes na época.

A autora consegue uma nova colocação profissional e deste modo parte para São Paulo, onde iria cuidar de seus "discípulos romanos", pois todos os filhos do patrão tinham nomes de personalidades romanas. Ela reclama do comportamento de seus alunos e da permissividade dos pais, relata ainda que todo preparo que adquiriu durante seus estudos era inviável para lidar com as crianças brasileiras de educação republicana. "Meus discípulos romanos são realmente muito mal-educados e preciso recorrer a variados recursos pedagógicos para tratar com eles... Os pais absolutamente não se incomodam com o comportamento das crianças e talvez isso esteja dentro dos "métodos republicanos" adotados pelo Sr. Costa" (BINZER, 1994: 108).

Autora relata que devido à falta de educação dos discípulos romanos e pela falta de limites dos pais, os meninos durante as festas juninas atiraram fogos contra os animais dos bondes o que acabou por quebrar as pernas desses animais. Binzer relata essa situação "enraiveceu demais o republicano pai dos romanos, que resolveu entregálos aos padres imediatamente, para serem educados; para Lavínia somente, não vale a 
pena manter uma educadora, e irá também para um colégio. Pobre Lavínia!” (BINZER, 1994: 116). Dessa forma, o pai foi obrigado a custear o preço do animal e motivado a entregar a educação dos meninos aos padres.

Isto posto, não valia a pena ter uma professora apenas para a menina uma vez que o ensino dos meninos era privilegiado em detrimento à educação das meninas, essas ideologias desvalorizavam as mulheres tanto no campo pessoal como profissional. Para Almeida "as construções ideológicas, que ao longo dos séculos foram baseadas na pretensa inferioridade das mulheres, determinam as representações sociais acerca da imagem feminina e presta-se para alimentar o controle sobre sua autonomia pessoal e profissional" (2006: 135).

Seu último emprego no Brasil foi à Fazenda São Sebastião, para Ina Von Binzer essa era a família mais simpática que conheceu e iria lecionar para três alunas que segundo relato da autora eram bem-comportadas e a patroa era diferente da maior parte das donas de casas brasileiras, pois exercia verdadeira fiscalização sob os empregados. A autora intriga-se com o preconceito do brasileiro em trabalhar, como se isso fosse nocivo a sua liberdade.

O norte americano respeita o trabalho e o trabalhador: ele próprio assume a direção dos trabalhos e toma parte em qualquer serviço, sem nenhum constrangimento, e se despreza o preto é apenas por julgá-lo inferior. O brasileiro, menos perspicaz e também mais orgulhoso, embora menos culto, despreza o trabalho e o trabalhador. Ele próprio não se dedica ao trabalho e se o pode evitar e encara a desocupação como um privilégio das criaturas livres. (BINZER, 1994: 153).

Ina Von Binzer durante sua estadia nesta fazenda percebe que os escravos são apenas para o serviço doméstico e o trabalho de fora é feito por homens livres ou por "camaradas" que são brasileiros geralmente mestiços de índios (os caboclos) ou são descendentes de portugueses imigrantes arruinados. A autora relata ainda que uma grande preocupação dos fazendeiros é a emancipação dos escravos, uma vez que onde iriam obter trabalhadores, pois os operários estrangeiros eram em geral caros demais, visto que os imigrantes vinham procurar ganhar quanto pudesse para fazer fortuna e voltar a sua terra natal. Com relação aos negros a autora descreve novamente a lei de emancipação de 28 de setembro de 1871 que determina que todas as crianças aprendam 
a ler e escrever, porém não existem talvez nem dez casas onde essa imposição seja atendida.

No interior, não há os mestres-escolas rurais como na nossa terra, e assim o fazendeiro ver-se-ia obrigado a selar vinte a cinquenta animais para levar os pretinhos à vila mais próxima, geralmente muito distante; ou então teriam de manter um professor especial para essa meninada?... Essas questões apresentam diversas soluções, mas o fato é que ninguém aqui faz coisa alguma, de maneira que as crianças nascem livres, mas crescem sem instrução e no futuro estarão no mesmo nível dos selvagens sem gozar nem mesmo das vantagens dos escravos, que aprendem este ou aquele trabalho material. Se já estão livres, porque fazer despesas com eles, desperdiçar dinheiro com quem não dará lucro. (BINZER, 1994: 128).

Nas instituições educacionais da época, somente as famílias das classes privilegiadas podiam prover educação aos seus filhos, desse modo não havia escolas para os negros. Contudo, em uma de suas cartas Ina Von Binzer relata que uma das escravas estava sendo alfabetizada pela senhora da fazenda.

Tinha aparecido dois camundongos na dispensa e, sem demora, D. Alfonsina chamou duas pretas e um preto dando-lhe ordem para esvaziá-la inteiramente, a fim de descobrir os buracos. Enquanto junto ao piano desafinado eu resignadamente contava o meu un, deux, trois - e Leonília, perseverantemente, cometia os mesmos erros - sob a ruidosa direção de D. Alfonsina erigia-se a volta de nós, uma barricada de caixões, barris, sacos etc.[...]. Para completar, uma mulatinha a qual D. Gabriela ensina a ler, devido a barricada que se empilhava no canto onde estuda, postou-se de repente atrás de minha cadeira soletrando o seu monótono b-a, ba b-é, bé, b-i bi! ... Era demais! Levantei-me furiosa, peguei as músicas, chamei Leonília e acabei a aula no salão, levaram isso a mal, e em toda essa história a desrespeitosa fui eu! (BINZER, 2010: 56).

Isto posto, é possível aventar que apesar de não ser uma prática comum, alguns escravos tinham contato, ainda que de forma precária, com a leitura e escrita. Uma probabilidade para a alfabetização dos escravos era que acompanhando as crianças à 
escola se presume que aprendiam escutando as lições direcionadas aos filhos de seus senhores.

Segundo Souza (1998) os negros eram marginalizados da vida social e profissional, não tendo espaço para eles na educação, no entanto a presença negra não era imperceptível e em algumas fotos do período é possível encontrar a figura de crianças negras. Somente em 1878 se inicia a criação dos cursos noturnos, direcionados aos escravos, que em algumas províncias eram incentivados a frequentar essas aulas. Para Souza (1998), os ideais do final do século XIX era exatamente reunir crianças pobres e ricas em um mesmo ambiente e com uma mesma educação, para prepará-los para a sociedade moderna, mas neste período infelizmente essa ideologia era apenas aspiração.

\section{Considerações Finais}

Analisar essa obra literária permitiu compreender alguns aspectos referentes à constituição histórica que abarcou o período de 1881 a 1884, época em que a preceptora esteve no Brasil.

Os textos literários permitem reconstruir as marcas do passado e grande parte dessas obras são repletos de tensões, conflitos e disputas. Entretanto, vale ressaltar que a literatura é um produto artístico e sua função é entreter o leitor, contudo é difícil redigir um texto literário sem levar em conta as condições sociais do período a que se refere a obra. Dessa forma, cabe ao historiador analisar esses escritos, com vistas a investigar as informações que são retratadas na obra, atribuindo-lhes significado.

Refletir como a literatura e os relatos memorialísticos se tornam fontes de investigações históricas possibilita um entendimento individualizado, pois segundo Alberti (1991) o indivíduo está interligado à cultura e marcado pela ideia de independente e autônomo, onde é possível reconhecer no sujeito o espaço da totalidade da cultura e da literatura dentro deste espaço.

E o que faz o escritor de autobiografia senão imprimir descontinuidades à sua vida, selecionando episódios 'significativos' que se encaixem na 'estrutura' do texto, para elaborar (no texto e de si mesmo) uma síntese (um concebido)? Isso acontece num movimento tal que esse 'semelhante' de si mesmo torna-se um 'indivíduo' único e totalizado, o sujeito 'psicológico', 
cuja constituição 'mítica' já foi inclusive sugerida por Lévi-Strauss ao final de sua análise sobre a cura xamanística: 'sabe-se bem que todo mito é uma procura do tempo perdido' (ALBERTI, 1991: 12).

Os autores de textos literários não são inspirados pelo acaso, mas estão inseridos dentro de uma cultura, uma sociedade e que desse modo, seus pontos de vistas com relação ao seu contexto social, político e moral são de alguma forma aportes para suas obras. Desejando ou não suas marcas estão impressas no texto.

Desse modo as fontes e objetos permitem o questionamento imprescindível para a história, segundo Hobsbawm (1991) não existe material histórico até que se faça uma pergunta, uma vez formulada a questão deposita-se as probabilidades de distintas respostas.

Diante do exposto intui-se que o olhar da autora representa uma importante declaração histórica sobre o Brasil e permite uma reflexão sobre o processo educacional, econômico e político do país, bem como uma ponderação acerca da escravidão, do papel das mulheres na sociedade no século XIX, a escolarização dos negros, à educação feminina e do diferentes pontos de vistas referentes aos imigrantes alemães.

Como aludido, não importa as dificuldades encontradas com relação a informações sobre a obra e autora, o livro traz valiosas informações de como era configurado o Brasil nesse período, bem como, as disputas políticas, econômicas e educacionais que transcursava o período em que Ina Von Binzer esteve aqui. Por intermédio de seu olhar pode-se observar o trabalho de uma preceptora imigrante, mulher, o final do século XIX, com detalhes sobre a sua rotina, alunos e sociedade.

Isto posto, a leitura do livro de Ina Von Binzer, sob o título de "Os meus romanos: alegrias e tristezas de uma educadora alemã no Brasil” descortinam elementos para investigação em distintas áreas como literatura, história, pedagogia e filosofia, entre outras, instituindo um acervo não esgotado de investigação que permite novas inquirições sobre quem foi Ina Von Binzer e qual eram suas aspirações pessoais e profissionais para vir ao Brasil? Qual era o método pedagógico que ela tanto desejava aplicar aos alunos brasileiros? Como esse método era aplicado na Alemanha? Seria possível confrontar essas metodologias? Enfim essas são algumas das questões que o livro provoca e que emergem outras discussões e análises. 


\section{Referências bibliográficas}

ALBERTI, Verena (1991). Literatura e Autobiografia: a questão do sujeito na narrativa. Estudos Históricos. Rio de Janeiro, vol. 4, n.7.

ALMEIDA, Jane Soares (2006). Vestígios para uma reinterpretação do magistério feminino em Portugal e no Brasil a partir do século XIX. In: SOUZA, R. F. de; VALDEMARIN, V. T; ALMEIDA, J. S de. O legado educacional do século XIX. Araraquara: UNESP.

BINZER, Ina Von (1991). Os meus romanos: alegrias e tristezas de uma educadora alemã no Brasil. Rio de Janeiro: Paz e Terra.

BOSI, Ecléa (1994). Memória e Sociedade: Lembrança dos Velhos. São Paulo: Companhia das Letras.

GONÇALVES, Luiz Alberto Oliveira (2000). Negros e educação no Brasil. In: LOPES, E. M. T.; FARIA FILHO, L. M.; VEIGA, C. G. (orgs.). 500 anos de educação no Brasil. Belo Horizonte: Autêntica, p. 95-134.

HOBSBAWM, Eric, J. (1990). A Outra História - algumas reflexões. In. KRANTZ, Frederick. (org.) A Outra História. Ideologia e protesto popular nos séculos XVII $e$ XIX. Rio de Janeiro: Jorge Zahar Ed.

LEUJENE, Philippe (2008) (org. Jovita Maria Gerheim). O pacto Autobiográfico, O Pacto Autobiográfico (Bis), Autobiografia e ficção. In:. O Pacto Autobiográfico: de Rousseau à Internet. Belo Horizonte: Ed. UFMG.

MONARCHA, Carlos (1999). Escola Normal da Praça: o lado noturno das luzes. Campinas, SP: Editora da Unicamp.

MORAES, C. S. V. (2006). O ideário republicano e a educação. Campinas: Mercado de Letras.

MORTATTI, M. R. L. (2000). Os sentidos da alfabetização. São Paulo (1876-1994). São Paulo: Unesp.

PESAVENTO, Sandra (set. 2003). O mundo como texto: leituras da História e da Literatura. História da Educação, ASPHE/FAE/UFPEL, Pelotas, n. 14, p. 31-45.

SEVCENKO, Nicolau (1983). Literatura como missão, tensões sociais e criação cultural na primeira república. São Paulo: Brasiliense.

SOUZA, R. F. (1998). Templos de civilização: a implantação da escola primária graduada no Estado de São Paulo. São Paulo: UNESP.

SOUZA, R. F. de; VALDEMARIN, V. T; ALMEIDA, J. S de. (2006). O legado educacional do século XIX. Araraquara: UNESP.

RITZKAT, Marly Gonçalves Bicalho (2000). Preceptoras alemãs no Brasil. In: LOPES, E. M. T.; FARIA FILHO, L. M.; VEIGA, C. G. (orgs.). 500 anos de educação no Brasil. Belo Horizonte: Autêntica, p. 95-134.

VALDEMARIN, V. T. (2004). Estudando as Lições de Coisas: análise dos fundamentos filosóficos do método de ensino intuitivo. Campinas: Autores Associados.

VIÑAO, Antônio (2004). Relatos e relações autobiográficas de professores e mestres. In. MENEZES, Maria Cristina (org.) Educação, memória, história. Campinas, SP: Mercado das Letras. 
Artigo recebido em 18 de dezembro de 2018.

Aprovado em 14 de fevereiro de 2020.

DOI: 10.12957/intellectus.2020.38993 